Article

\title{
Industrial Wastewater Treatment by Nanofiltration-A Case Study on the Anodizing Industry
}

\author{
Aamer Ali, Maria C. Nymann, Morten L. Christensen ${ }^{\circledR}$ and Cejna A. Quist-Jensen * \\ Center for Membrane Technology, Department of Chemistry and Bioscience, Aalborg University, Fredrik Bajers \\ Vej 7H, 9220 Aalborg East, Denmark; aa@bio.aau.dk (A.A.); maria.nymann@hotmail.com (M.C.N.); \\ mlc@bio.aau.dk (M.L.C.) \\ * Correspondence: cejna@bio.aau.dk
}

Received: 17 March 2020; Accepted: 27 April 2020; Published: 29 April 2020

check for updates

\begin{abstract}
The anodizing industry generates several alkaline and acidic wastewater streams often with high concentrations of heavy metals. In this study, nanofiltration (NF) was used to treat wastewater from individual baths, i.e., wastewater from color rinse, alkaline pickling rinse, acidic pickling rinse and anodizing rinse, as well as a mixture of all the wastewater streams. The experiments were carried out by using a commercial membrane (NF99HF) exhibiting pure water permeability of $10 \mathrm{~L} /\left(\mathrm{m}^{2} \cdot \mathrm{h} \cdot \mathrm{bar}\right)$. For all wastewater streams except one, $\mathrm{pH}$ was adjusted to bring it within the recommended $\mathrm{pH}$ limits of the membrane, whereby part of the heavy metals precipitated and was removed. The NF of the color rinse offered high-quality permeate (heavy metals below detection limit) and high permeability $\left(9 \mathrm{~L} /\left(\mathrm{m}^{2} \cdot \mathrm{h} \cdot \mathrm{bar}\right)\right)$, whereas the nanofiltration of the alkaline pickling rinse exhibited no permeability. The NF of the acidic pickling rinse showed a permeability of $3.1-4.1 \mathrm{~L} /\left(\mathrm{m}^{2} \cdot \mathrm{h} \cdot \mathrm{bar}\right)$, but low ion rejection (7-13\%). NF of the neutralized mixed wastewater, after the removal of precipitate, produced high-quality permeate with a stable permeability of $1 \mathrm{~L} /\left(\mathrm{m}^{2} \cdot \mathrm{h} \cdot \mathrm{bar}\right)$. Treatment of the mixed wastewater is therefore the best option if the water has to be discharged. If the water has to be reused, the permeate conductivity in the color rinse and anodizing rinse baths have been reduced significantly, so the treatment of these streams may then be a better option.
\end{abstract}

Keywords: nanofiltration; anodizing; wastewater; heavy metals; water reuse; membranes

\section{Introduction}

Anodizing is an important process to provide superior esthetic and anti-corrosion properties to various metallic surfaces. In addition to the main anodizing step, the overall process consists of several pre and post-treatments [1]. The main pretreatments include degreasing and pickling aimed at removing mainly grease and the metal oxide layer from the surface. Coloring and sealing are performed as the main post treatment steps with objective of coloring and closure of the surface pores, respectively [2]. After completing each step, aluminum parts are moved to rinsing baths to remove residuals. Thus, each rinsing step produces both alkaline and acidic wastewater streams, which contain heavy metals such as chromium, lead, zinc, copper and manganese, often in higher quantities than the permitted limits for discharge [3]. Heavy metals might accumulate in living organism and have serious impacts even when present in trace concentrations [4]. Thus, the discharge of these streams into the environment is a concern, meaning that proper treatments are needed before discharge [5].

Traditionally, the effluents from the anodizing industry are treated by operations involving neutralization, flocculation, settling and press filtration and the sludge is often disposed on land [6]. Generally, the acidic and alkaline streams are collected separately and fed to the treatment plant 
in a controlled flow for neutralization $[7,8]$. An additional neutralization step might be needed depending upon the degree of neutralization achieved after mixing acidic and alkaline streams in the treatment plant. Subsequently, the wastewater is added to a coagulation process followed by the settling. The sediments from the settling tank are introduced into a filter press to achieve a final solid concentration as high as 30\% [7]. However, the process consumes large amounts of chemicals, generates secondary waste such as hydroxides and has large footprints $[9,10]$. Moreover, the final effluent still might contain heavy metals in trace quantities [11].

Membrane processes have gained significant attention as a replacement of traditional unit operations in desalination and wastewater treatment [12] due to their compact size, less energy intensive nature, efficient separation capabilities and environmental friendly nature due to less chemical consumption. Nanofiltration (NF) is a pressure-driven membrane process with separation efficiency between reverse osmosis and ultrafiltration. NF is generally carried out by using asymmetric polymeric membranes consisting of a functionally active porous top layer with a low resistance support layer. Typical pores in the active layer are around $1 \mathrm{~nm}$ in size and have fixed charges. Thus, in addition to the sieving mechanism, the surface charge of the support layer allows rejecting charged ions with a size smaller than the membrane pore size. These characteristics enable NF to retain multivalent ions while allowing the passage of small uncharged species and monovalent ions. This aspect, combined with low energy consumption compared to reverse osmosis, makes NF promising for the rejection of heavy metals from wastewater $[13,14]$. For the treatment of complex wastewaters, NF has been investigated as a standalone process [15-18] as well as in integration with other treatment methods such as coagulation and ultrafiltration $[19,20]$.

In the current study, NF has been applied for the treatment of wastewater streams from a Danish anodizing industry according to point source (the treatment of individual streams at their point of origin) and end-of-pipe (the treatment of mixed streams at a centralized location) treatment strategies. In the first scenario, various individual wastewater streams, including color rinse, alkaline pickling rinse, acidic pickling rinse and anodizing rinse, have been treated separately through NF. According to the second protocol, all streams have been collected to make a mixed wastewater stream before treatment. Based upon the rejection of various ions and the process stability, the optimum treatment scenario has been identified. The study has been carried out by using a commercial NF99HF membrane, due to its reported high flux in desalination and wastewater treatment applications [21].

\section{Materials and Methods}

\subsection{Wastewater Analysis}

Wastewater was collected from four rinse baths: color rinse, alkaline pickling rise, acidic pickling rinse and anodizing rinse, as well as from a centralized container where wastewater from the individual baths was mixed (Figure 1) and neutralized. The collected wastewater streams were characterized in terms of ionic composition, water activity, $\mathrm{pH}$, conductivity and dry matter content. The ionic compositions were measured with an inductively coupled plasma spectrometer (ICP) (iCap 6300 DUO; Thermo Scientific, Waltham, MA, USA). The samples were measured in radial view. A total of $1 \mathrm{ppm}$ Yttrium was used as the internal standard. All ICP measurements were made in duplicates. Water activity was measured at $25^{\circ} \mathrm{C}$ by the dew point method using a chilled mirror (Aqualab 4TE). Dry matter was determined by the weight loss using $10 \mathrm{~mL}$ of sample for $24 \mathrm{~h}$ at $105^{\circ} \mathrm{C}$. The absorbance of the color rinse solution was measured by UV-Vis spectrophotometer (Thermo Fisher scientific) at $660 \mathrm{~nm}$. 


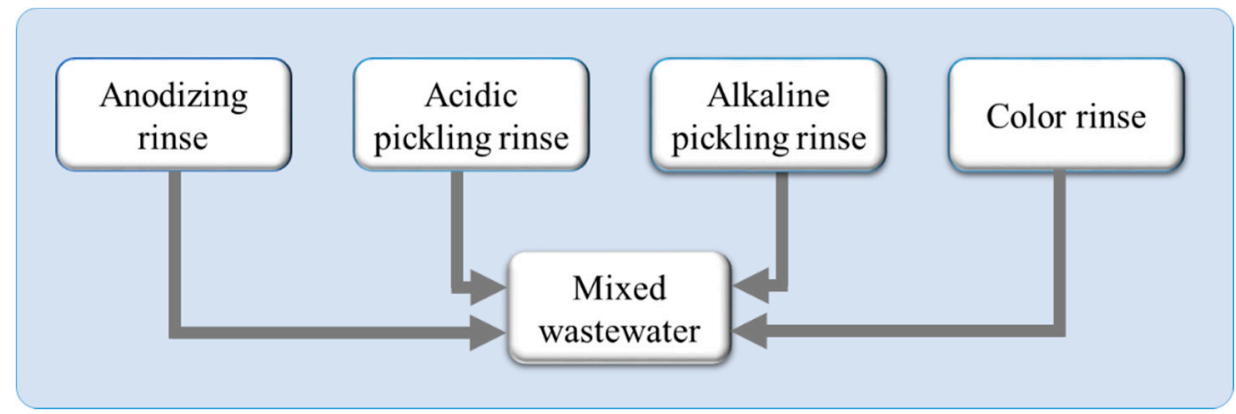

Figure 1. Overview of the different solutions treated with nanofiltration (NF).

The measured characteristics of the wastewater streams are listed in Table 1. Due to the extreme $\mathrm{pH}$ of the alkaline pickling rinse, acidic pickling rinse and the anodizing rinse, it was necessary to adjust $\mathrm{pH}$ to bring it within the safe operating range of NF membrane (defined by the manufacture). Potentiometric titrations were performed using Titralab ${ }^{\mathrm{TM}} 900$ equipment from Radiometer, Brønshøj, Denmark, using either $2 \mathrm{M} \mathrm{H}_{2} \mathrm{SO}_{4}$ or $2 \mathrm{M} \mathrm{NaOH}$ as titrant. $\mathrm{pH}$ was measured using an SI Analytics Blue Line $17 \mathrm{pH}$ glass electrode calibrated against standard buffer solution at $\mathrm{pH} 4$ and 7 . Depending on $\mathrm{pH}$, the wastewater was adjusted with $\mathrm{H}_{2} \mathrm{SO}_{4}$ or $\mathrm{NaOH}$ up to $\mathrm{pH} 4$ or down to $\mathrm{pH} 9.5$ (safe operating window of the applied membrane) and prior to nanofiltration, the removal of precipitants was performed through centrifugation (Thermo Scientific) after $\mathrm{pH}$ adjustment.

Table 1. Composition and characteristics of the different wastewater solutions.

\begin{tabular}{cccccc}
\hline & Color Rinse & $\begin{array}{c}\text { Alkaline } \\
\text { Pickling Rinse }\end{array}$ & $\begin{array}{c}\text { Acidic } \\
\text { Pickling Rinse }\end{array}$ & $\begin{array}{c}\text { Anodizing } \\
\text { Rinse }\end{array}$ & $\begin{array}{c}\text { Mixed } \\
\text { Wastewater (W) }\end{array}$ \\
\hline pH & 7.4 & 12.7 & 1.2 & 1.52 & 7.5 \\
Conductivity [mS/cm] & 0.06 & 35.9 & 76.1 & 24.1 & 6.7 \\
Dry matter [\%] & 0 & 6.0 & 0 & 0.7 & 0.7 \\
Water activity & N.A. & 0.9837 & 0.9964 & 0.9992 & 0.9977 \\
$\mathrm{Al}[\mathrm{ppm}]$ & 0.0838 & 9040.6 & 56.78 & 510.84 & 0.678 \\
$\mathrm{As}[\mathrm{ppm}]$ & 0.149 & $\mathrm{~N} . \mathrm{D}$ & $\mathrm{N} . \mathrm{D}$ & $\mathrm{N} . \mathrm{D}$ & 0.093 \\
$\mathrm{Cr}[\mathrm{ppm}]$ & 0.962 & 2.36 & 0.56 & 0.38 & N.D \\
$\mathrm{Cu}[\mathrm{ppm}]$ & $\mathrm{N} . \mathrm{D}$ & 0.36 & 1.33 & 2.05 & N.D \\
$\mathrm{Fe}[\mathrm{ppm}]$ & $\mathrm{N} . \mathrm{D}$ & 3.35 & 5.06 & 2.95 & N.D \\
$\mathrm{Mg}[\mathrm{ppm}]$ & $\mathrm{N} . \mathrm{D}$ & 1.31 & 18.43 & 8.62 & 2.74 \\
$\mathrm{Mn}[\mathrm{ppm}]$ & 0.0108 & 2.23 & 2.82 & 2.39 & 0.092 \\
$\mathrm{Na}[\mathrm{ppm}]$ & 11.19 & 4275.7 & 43.07 & 20.65 & N.A \\
$\mathrm{Ni}[\mathrm{ppm}]$ & $\mathrm{N} . \mathrm{D}$ & $\mathrm{N} . \mathrm{D}$ & 4.69 & $\mathrm{~N} . \mathrm{D}$ & N.D \\
$\mathrm{P}[\mathrm{ppm}]$ & 0.183 & 46.30 & 0.48 & 0.63 & N.D \\
$\mathrm{Pb}[\mathrm{ppm}]$ & $\mathrm{N} . \mathrm{N}$ & $\mathrm{N} . \mathrm{D}$ & $\mathrm{N} . \mathrm{D}$ & $\mathrm{N} . \mathrm{D}$ & N.D \\
$\mathrm{Zn}[\mathrm{ppm}]$ & $\mathrm{N} . \mathrm{D}$ & 0.24 & 10.51 & 1.34 & N.D. \\
$\mathrm{Cl}[\mathrm{ppm}]$ & 8 & 623.6 & 33.78 & 5.68 & N.A \\
$\mathrm{NO}[\mathrm{ppm}]$ & $\mathrm{N}$ & $\mathrm{N} . \mathrm{D}$ & 9.66 & $\mathrm{~N} . \mathrm{D}$ & N.A \\
$\mathrm{NO}$ [ppm] & $\mathrm{N} . \mathrm{D}$ & 150.8 & 3858 & 36.7 & N.A \\
$\mathrm{SO}$ [ppm] & 37.64 & 64.2 & 16.1 & 3570 & N.A \\
\hline
\end{tabular}

N.A: Not analyzed, N.D: Below detection limit.

\subsection{NF Tests}

NF tests on all wastewater streams were carried out at a low pressure of 3.5 bar by using a setup containing an Alfa Laval LabStak M10 crossflow module (Figure 2) with a crossflow pump (ZUWA, Nirostar, Austria) as well as two pressure gauges (Danfoss, Pressure Transmitter). The effective membrane area of the M10 module was $0.0168 \mathrm{~m}^{2}$. The crossflow was $1 \mathrm{~L} / \mathrm{min}$. The membranes were the Alfa Laval-NF99HF flat sheet thin film composite membrane with a pore radius around $0.43 \mathrm{~nm}$ according to Oatley et al. [22] and a recommended $\mathrm{pH}$ range of 3 to 10 [23]. New membranes were used for each experiment and each membrane was activated according to the procedure provided by 
the manufacturer. First, the membranes were rinsed with distillate water and then a warm $\left(30-55^{\circ} \mathrm{C}\right)$ solution of distillate water was introduced into the system. Afterwards, the membranes were rinsed with a solution of $\mathrm{NaOH}$ ( $\mathrm{pH} 8.5-10.5)$ for $30 \mathrm{~min}$ and finally rinsed with distillate water until neutral $\mathrm{pH}$. Hereafter, the different feed solutions were introduced into the system with an initial volume of 3 L for all the experiments.

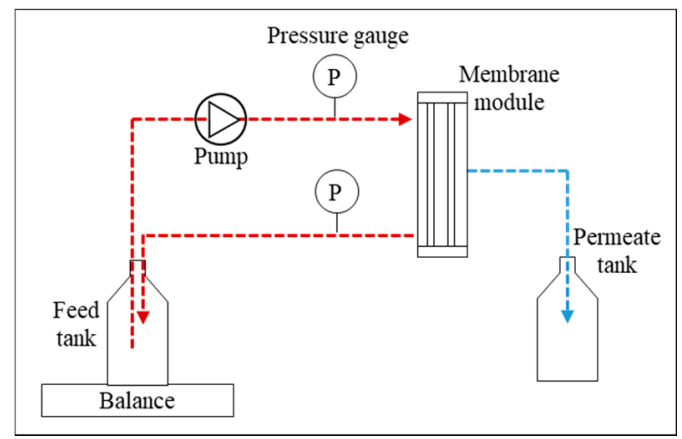

Figure 2. Schematic overview of the NF system.

Rejections were calculated from Equation (1). The concentration of ions in permeate and retentate were measured several times during the experiment.

$$
R=1-\frac{C_{p}}{C_{r}}
$$

where $C_{p}$ and $C_{r}$ are the concentration in permeate and retentate, respectively.

\section{Results and Discussion}

\subsection{Effect of $p H$ Adjustment}

Prior to NF, pH was adjusted to 9.5, 4.2 and 4.0 for the alkaline pickling rinse, acidic pickling rinse and the anodizing rinse, respectively. The titration curve for the alkaline pickling rinse, acidic pickling rinse and the anodizing rinse, showed the required amount of $\mathrm{NaOH}$ or $\mathrm{H}_{2} \mathrm{SO}_{4}$ for the $\mathrm{pH}$ adjustment (Figure 3).

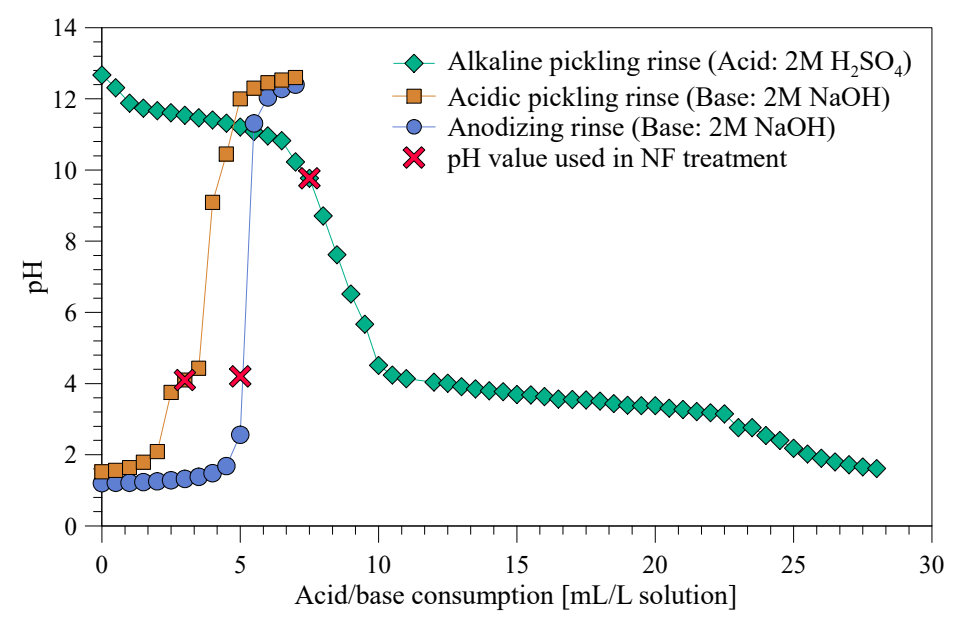

Figure 3. Titration curve for some of the wastewater samples.

As a result of $\mathrm{pH}$ adjustment, precipitate was formed and removed through centrifugation. For the alkaline pickling rinse, the dry matter content (total dissolved solid content) was thereby reduced from $6 \%$ to $3.6 \%$, i.e., $24 \mathrm{~g}$ of dry material was removed per $\mathrm{kg}$ of wastewater (Tables 1 and 2 ). As a 
result, water activity increased from 0.98 to 0.99 (Tables 1 and 2). The ICP results for the alkaline pickling rinse were also measured before and after $\mathrm{pH}$ adjustment and showed that all heavy metals, e.g., $\mathrm{Cr}, \mathrm{Cu}$ and $\mathrm{Mn}$, were precipitated and removed (Tables 1 and 2). The concentration of $\mathrm{Al}$ and $\mathrm{P}$ in effluent was reduced with $99.5 \%-99.7 \%$, and the $\mathrm{Al}$ accounts for $40 \%$ of the dry material removed. Assuming that all $\mathrm{Al}$ is precipitated as $\mathrm{AlOOH}$, it results in $20 \mathrm{~g}$ of dry material per $\mathrm{kg}$ of wastewater, and, assuming that all $\mathrm{Al}$ precipitate as $\mathrm{Al}(\mathrm{OH})_{3}$, it results in $26 \mathrm{~g}$ per $\mathrm{kg}$ of wastewater, which agrees well with the measured dry matter content before and after $\mathrm{pH}$ adjustment. Na concentration declined due to dilution during $\mathrm{pH}$ adjustment. The measured buffer capacity at $\mathrm{pH} 11.5$ may be due to precipitation (Figure 3). Dissolved aluminium exists as $\mathrm{Al}(\mathrm{OH})_{4}{ }^{-}$at high $\mathrm{pH}$ and has to be neutralized if aluminium is precipitated, i.e., 1 mole of $\mathrm{H}_{2} \mathrm{SO}_{4}$ is required to neutralize 2 moles of $\mathrm{Al}(\mathrm{OH})_{4}{ }^{-}$. The total concentration of aluminium prior to $\mathrm{pH}$ adjustment was $0.33 \mathrm{M}$.

For acidic pickling rinse, the dry matter content of the sample increased from $0 \%$ to $1.6 \%$ after the addition of $\mathrm{NaOH}$, meanwhile the activity remained almost the same. Comparing the ICP results before and after $\mathrm{pH}$ adjustment showed that the concentration of ions decreased marginally, whereas $\mathrm{Na}$ increased by more than 70 times due to the addition of $\mathrm{NaOH}$. Precipitate was formed after $\mathrm{pH}$ adjustment and after centrifugation as $15 \%$ of the iron was removed $(0.7 \mathrm{ppm})$ and $6 \%$ of the aluminum was removed (3.3 ppm). The precipitation of iron or aluminum may also explain the buffer effect around $\mathrm{pH}$ 4. For the anodizing rinse, $\mathrm{NaOH}$ addition increased the dry matter content from 0.7 to $1.1 \%$, whereas the conductivity dropped from 24.1 to $10 \mathrm{mS} / \mathrm{cm}$. The higher dry matter content was, again, an effect of the addition of $\mathrm{NaOH}$, and the reduced conductivity, which may largely be an effect of the lower concentration of $\mathrm{H}^{+}$after $\mathrm{pH}$ adjustment. The conductivity of hydrochloric acid was $26 \mathrm{~S}$ $\mathrm{cm}^{-1}$ at $\mathrm{pH} 1.2$ assuming a molar conductance of $400 \mathrm{~S} \mathrm{~mol}^{-1} \mathrm{~cm}^{2}$. There were no significant changes to other ions except Na. The mixed wastewater already contained large amounts of precipitate due to the $\mathrm{pH}$ neutralization of the wastewater. The composition of the mixed wastewater was measured both before (W-Table 1 ) and after centrifugation ( $\mathrm{W}^{*}$ - Table 2). Neither $\mathrm{Cr}, \mathrm{Cu}, \mathrm{Fe}, \mathrm{Ni}, \mathrm{P}, \mathrm{Pb}$ nor $\mathrm{Zn}$ were detected in the mixed wastewaters $\left(\mathrm{W}\right.$ and $\left.\mathrm{W}^{*}\right)$, as the company neutralizes $\mathrm{pH}$ and remove the ions as precipitates.

Table 2. Characteristics after $\mathrm{pH}$ adjustment and for the mixed wastewater after centrifugation.

\begin{tabular}{|c|c|c|c|c|}
\hline & $\begin{array}{c}\text { Alkaline } \\
\text { Pickling Rinse }^{\mathrm{a}}\end{array}$ & $\begin{array}{c}\text { Acidic Pickling } \\
\text { Rinse }^{a}\end{array}$ & Anodizing Rinse ${ }^{a}$ & $\begin{array}{c}\text { Mixed } \\
\text { Wastewater }\left(\mathbf{W}^{*}\right)^{b}\end{array}$ \\
\hline $\mathrm{pH}$ & 9.5 & 4.2 & 4.0 & 7.5 \\
\hline Conductivity [mS/cm] & 36 & 18 & 10 & 7 \\
\hline Dry matter [\%] & 3.6 & 1.6 & 1.1 & 0.5 \\
\hline Water activity & 0.9924 & 0.9959 & 0.9991 & 0.9993 \\
\hline $\mathrm{Al}[\mathrm{ppm}]$ & 37.11 & 50.02 & 488.34 & N.D \\
\hline As [ppm] & N.D. & N.D. & N.D. & 0.022 \\
\hline Cr [ppm] & N.D. & 0.48 & 0.37 & N.D \\
\hline $\mathrm{Cu}[\mathrm{ppm}]$ & N.D. & 1.22 & 1.99 & N.D \\
\hline $\mathrm{Fe}[\mathrm{ppm}]$ & 0.021 & 4.02 & 2.93 & N.D \\
\hline $\mathrm{Mg}$ [ppm] & N.D. & 16.97 & 8.60 & 2.68 \\
\hline Mn [ppm] & N.D. & 2.61 & 2.40 & 0.035 \\
\hline $\mathrm{Na}[\mathrm{ppm}]$ & 4205.6 & 3138.6 & 1882.1 & 2016.0 \\
\hline $\mathrm{Ni}[\mathrm{ppm}]$ & N.D. & N.D. & N.D. & N.D \\
\hline $\mathrm{P}[\mathrm{ppm}]$ & 0.16 & 3.7 & 0.65 & 0.068 \\
\hline $\mathrm{Pb}[\mathrm{ppm}]$ & N.D. & N.D. & N.D. & N.D \\
\hline $\mathrm{Zn}[\mathrm{ppm}]$ & N.D. & 10.06 & 1.31 & N.D \\
\hline
\end{tabular}

${ }^{\mathrm{a}}$ after $\mathrm{pH}$ adjustment, ${ }^{\mathrm{b}}$ after centrifugation, N.A: Not analyzed, N.D: Not detected.

\subsection{Nanofiltration of Various Wastewaters}

It was possible to remove contaminants with $\mathrm{pH}$ adjustment, but it was not possible to remove all critical heavy metals; thus, NF was tested as an alternative or supplementary method. All the baths 
were treated through NF in order to find the optimum scenario for wastewater treatment. For mixed wastewater, two tests were performed, i.e., one where the wastewater was used as such and another test, where it was centrifuged prior to use.

The water permeability of the membrane was measured to $11 \mathrm{~L} /\left(\mathrm{m}^{2} \cdot \mathrm{h} \cdot \mathrm{bar}\right)$. Other studies of the permeability for these membranes are in the range of $9-18 \mathrm{~L} /\left(\mathrm{m}^{2} \cdot \mathrm{h} \cdot \mathrm{bar}\right)$ [24]. Thus, the permeability in this study is in the lower end of the range, but still reasonable.

The permeability values for all the different bath experiments are shown in Figure 4. The experimental time was prolonged for the baths, which showed promising results in terms of permeability and rejections (color rinse and mixed wastewater after centrifugation). The permeability for NF of the color rinse was measured to be $9 \mathrm{~L} /\left(\mathrm{m}^{2} \cdot \mathrm{h} \cdot \mathrm{bar}\right)$ but started to drop at the end of the experiment. The achieved recovery factor (RF) of the color rinse was $88.1 \%$. The permeability was higher than the other wastewater streams, which corresponds to the low conductivity of the color rinse $(\sim 0.06 \mathrm{mS} / \mathrm{cm})$. The NF of acidic pickling rinse showed a declining permeability that ends at $3.2 \mathrm{~L} /\left(\mathrm{m}^{2} \cdot \mathrm{h} \cdot \mathrm{bar}\right)$ and an RF of $31.4 \%$. The NF of the mixed wastewater showed a stable permeability around $1.5 \mathrm{~L} /\left(\mathrm{m}^{2} \cdot \mathrm{h} \cdot \mathrm{bar}\right)$, with an $\mathrm{RF}$ of $13.9 \%$ if the precipitate was removed prior to filtration. For the three other baths (alkaline pickling rinse, anodizing rinse and the mixed wastewater without centrifugation), the permeability was lower than $0.5 \mathrm{~L} /\left(\mathrm{m}^{2} \cdot \mathrm{h} \cdot \mathrm{bar}\right)$ and these baths are not efficiently treated since they have an RF value below 4.5\%. In particular, for the alkaline pickling rinse, no permeate was observed at 3.5 bar.

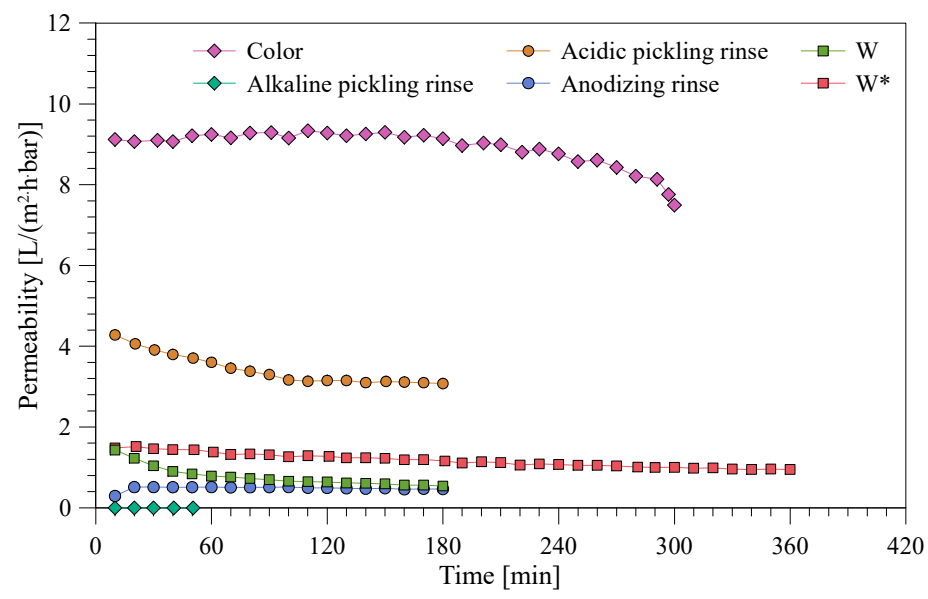

Figure 4. Permeability during the NF treatment of different baths from the anodizing.

The conductivity of the feed solution and permeate was measured during the experiment (Figure 5). The conductivity of the color rinse was lower compared to the other baths and the feed conductivity increased from 0.06 to $0.29 \mathrm{mS} / \mathrm{cm}$, which corresponds to an ion rejection between $67 \%$ and $92 \%$ during the experiment. The conductivity of the permeate was $0.02 \mathrm{mS} / \mathrm{cm}$. The rejection of ions, when filtering the acidic pickling rinse, was low and measured to $7 \%$ to $13 \%$. The used membrane has an isoelectric point between 4.12-4.42 [22]. The treatment of the acidic pickling rinse was carried out in the range of the isoelectric point, i.e., at $\mathrm{pH} 4.2$; thus, below this $\mathrm{pH}$, the membrane is positively charged. The reason for the low rejection, measured through the conductivity, may be due to the high concentration of both $\mathrm{NO}_{3}{ }^{-}$and $\mathrm{Na}^{+}$(3858 and 3139 ppm-Tables 1 and 2), which is easily transported through the neutrally charged membrane, as both nitrate and sodium ions are well below the pore size of the membrane. The anodizing rinse showed an ion rejection of $80 \%$ in the beginning of the experiment, which drops to $58 \%$ due to the increase in the conductivity in the permeate. The ionic strength increases when ions are concentrated in the feed in which the electric double layer is compressed, e.g., in the pores, which may explain the lower rejection of ions (Figure 5b). The mixed wastewater solution both before and after centrifugation showed a stable ion rejection of around $64 \%$ during the experiments. 


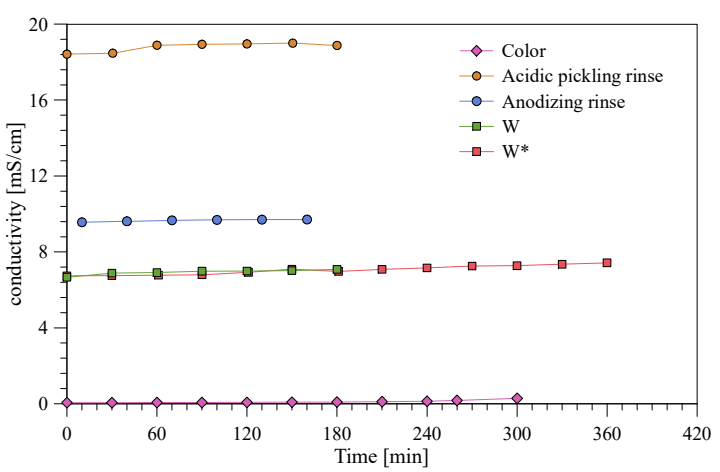

(a)

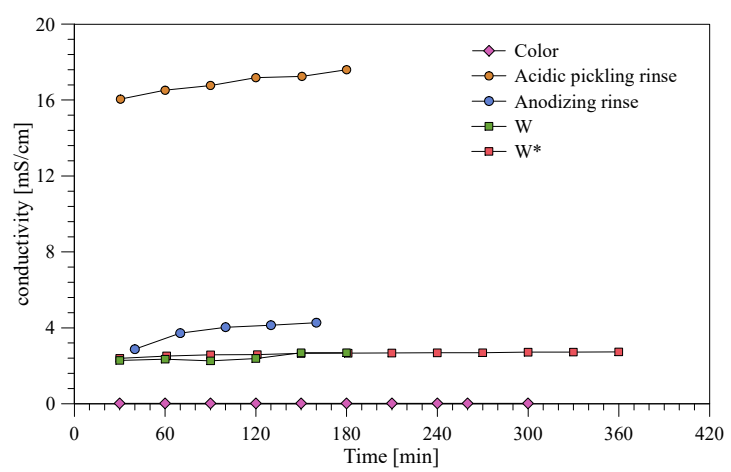

(b)

Figure 5. Conductivity of (a) feed and (b) permeate for the different baths.

An ICP was used to determine the concentration of the ions in feed and permeate. From the ICP data, the rejection was calculated for each ion (Figure 6). The rejection is the average rejection of each ion during the experiment. For the acidic pickling rinse, the rejection of $\mathrm{Na}$ was $31 \%$ and the rejection of $\mathrm{Cu}$ was $67 \%$, while the rejection of the other ions ranged from $80 \%$ to $100 \%$. The NF of anodizing rinse, mixed wastewater without centrifugation and the mixed wastewater with centrifugation showed high rejections even for $\mathrm{Na}(57 \%, 69 \%$ and $70 \%$, respectively). For mixed wastewater, both with and without centrifugation, the rejection of $\mathrm{Mg}$, $\mathrm{Mn}$ and As was higher than $80 \%$ and none of the heavy metals were detected in the permeate.

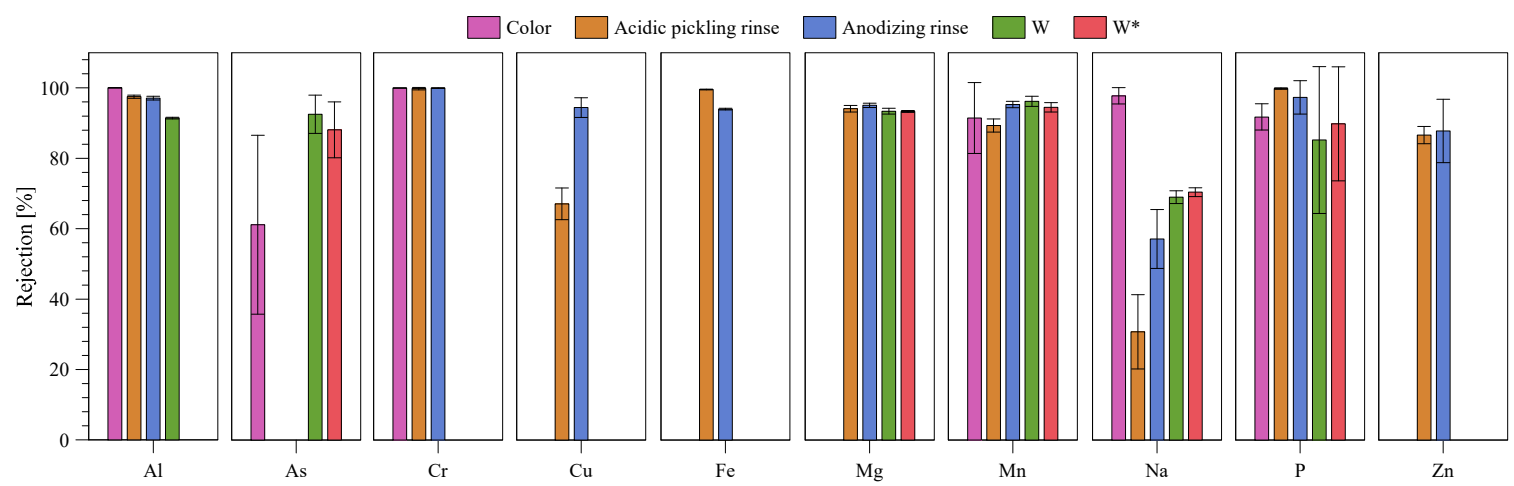

Figure 6. Rejection of each ion for the different baths. Rejection is not shown for some baths where the concentration of ions is below the detection limit in both the feed and permeate.

To test if the membrane rejected color from the color rinse bath, the color change was observed during the experiment both visually (Figure 7) and through absorbance (Figure 8), which proved that no color was transported through the membrane. The concentrated color rinse can potentially be reused as a new color bath.

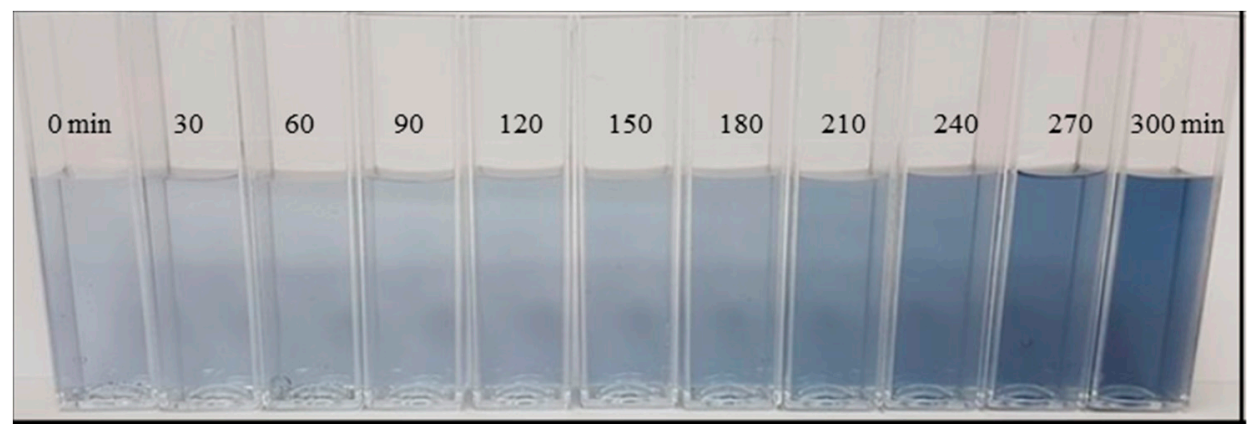

Figure 7. Change in concentration of the color rinse bath during filtration. 


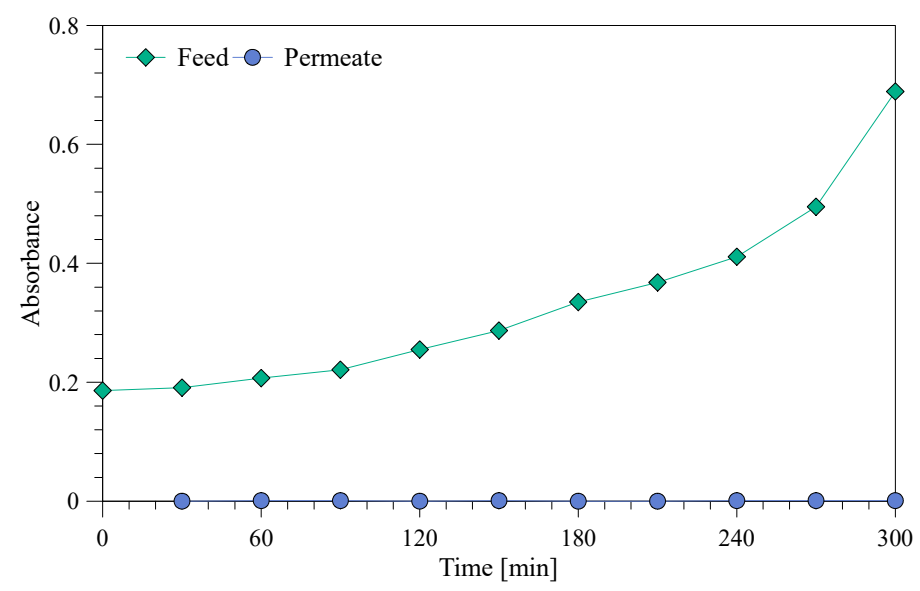

Figure 8. Absorbance during treatment of the color rinse (measured at $610 \mathrm{~nm}$ ).

\subsection{Permeate Quality}

The permeate quality was tested by measuring the final ion concentration in the permeate stream (Figure 9). The discharge limit given by Danish standards [25] is illustrated as a black line, and it is seen that only $\mathrm{Cu}$ concentrations, in the acidic pickling rinse and in the anodizing rinse, are exceeding the maximum concentration. Additionally, the permeate quality meets the criteria for discharge. For water reuse, other criteria may be relevant depending on the industry.

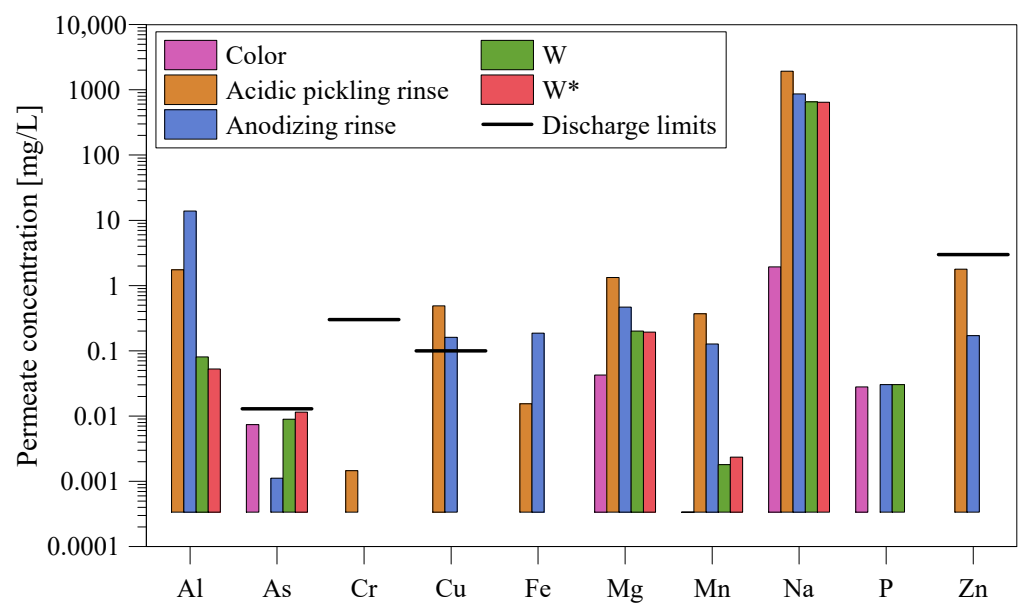

Figure 9. Permeate quality for the different baths.

\section{Conclusions}

Nanofiltration was used for both point source and the end-of-the-pipe treatment of wastewater from the anodizing industry. $\mathrm{pH}$ adjustment was required for the alkaline, acidic and anodizing waste streams to avoid damaging the membrane. For the alkaline stream, $\mathrm{pH}$ adjustment resulted in the precipitation of dry matter, including heavy metals, in a significant quantity ( $40 \%)$. However, the alkaline stream could not be filtered through the NF membrane. For wastewater from the color rinse bath, NF showed stable flux and good-quality permeate with a low concentration of heavy metals and very low electrical conductivity. The acidic pickling rinse showed a slight decrease in NF permeability over time and a high rejection of cations; however, the concentration of $\mathrm{Cu}$ remained above the recommended discharge limit. NF exhibited stable flux for anodizing rinse and showed high rejection towards various ions but also with a $\mathrm{Cu}$ concentration slightly higher than the allowable discharge limit. No heavy metals were detected in NF permeate of the neutralized mixed wastewater. Furthermore, the flux remained stable for the mixed wastewater if large particles were removed before NF. Therefore, end-of-the-pipe treatment appears to be more promising than point source treatment 
for discharge purposes. For water reuse, the treatment of the color rinse and anodizing rinse baths may be a better solution, because permeate with low conductivity can be produced. Thus, the final treatment strategy should be adopted according to the final aim, i.e., reuse or discharge.

Author Contributions: Conceptualization, M.L.C. and C.A.Q.-J.; validation, A.A. and M.C.N.; formal analysis, A.A. and M.C.N.; investigation, M.C.N.; writing-original draft preparation, A.A.; writing-review and editing, A.A., M.L.C. and C.A.Q.-J.; visualization, A.A. and C.A.Q.-J.; supervision, M.L.C. and C.A.Q.-J.; All authors have read and agreed to the published version of the manuscript.

Funding: This research received no external funding.

Acknowledgments: The Danish Anodizing Industry (DAI) is greatly acknowledge for providing the wastewater.

Conflicts of Interest: The authors declare no conflict of interest.

\section{References}

1. Stevenson, M.F. Anodizing. In ASM Handbook; ASM International: Materials Park, OH, USA, 1994; Volume 5, pp. 482-493.

2. Grubbs, C.A. Anodizing of aluminum. Met. Finish. 1999, 97, 476-493. [CrossRef]

3. Barakat, M. New trends in removing heavy metals from wastewater. Arab. J. Chem. 2011, 4, 361-377. [CrossRef]

4. Lin, X.; Burns, R.C.; Lawrance, G.A. Heavy Metals in Wastewater: The effect of electrolyte composition on the precipitation of cadmium (II) using lime and magnesia. Water. Air. Soil Pollut. 2005, 165, 131-152. [CrossRef]

5. Update, T.I. The Environmental Impact of Anodizing. Available online: https://www.thomasnet.com/articles/ custom-manufacturing-fabricating/anodizing-environmental (accessed on 20 September 2019).

6. Correia, A.; Chambino, T.; Gonc, L.; Franco, A.; Gonc, R.; Limpo, V.; Delmas, F.; Nogueira, C.; Bartolomeu, F. Municipal wastewater treatment with anodizing solid waste. Desalination 2005, 185, 341-350. [CrossRef]

7. Chambino, T.; Correia, A.; Barany, S. Aluminium salts hydrolysis products from industrial anodising sludges in wastewater treatment. Prog. Colloid Polym. Sci. 2008, 5, 65-69.

8. Magalhães, J.M.; Silva, J.E.; Castro, F.P.; Labrincha, J.A. Physical and chemical characterisation of metal finishing industrial wastes. J. Environ. Manag. 2005, 75, 157-166. [CrossRef] [PubMed]

9. Matlock, M.M.; Howerton, B.S.; Atwood, D.A. Chemical precipitation of heavy metals from acid mine drainage. Water Res. 2002, 36, 4757-4764. [CrossRef]

10. Amer, S. Treating Metal Finishing Wastewater; AQUACHEM INC.: Denver, CO, USA, 1998; pp. 1-7.

11. Dabrowski, A.; Robens, E. Selective removal of the heavy metal ions from waters and industrial wastewaters by ion-exchange method. Chemosphere 2004, 56, 91-106. [CrossRef] [PubMed]

12. Drioli, E.; Ali, A.; Macedonio, F. Membrane Operations for Process Intensification in Desalination. Appl. Sci. 2017, 7, 100. [CrossRef]

13. Fane, A.G.; Awang, A.R.; Bolko, M.; Macoun, R.; Schofield, R.; Shen, Y.R.; Zha, F. Metal recovery from wastewater using membranes. Water Sci. Technol. 1992, 25, 5-18. [CrossRef]

14. Andrade, L.H.; Aguiar, A.O.; Pires, W.L.; Miranda, G.A.; Teixeira, L.P.T.; Almeida, G.C.C.; Amaral, M.C.S. Nanofiltration and reverse osmosis applied to gold mining effluent treatment and reuse. Braz. J. Chem. Eng. 2017, 34, 93-107. [CrossRef]

15. Liu, F.; Zhang, G.; Meng, Q.; Zhang, H. Performance of Nanofiltration and Reverse Osmosis Membranes in Metal Effluent Treatment. Chin. J. Chem. Eng. 2008, 16, 441-445. [CrossRef]

16. Muthukrishnan, M.; Guha, B.K. Effect of $\mathrm{pH}$ on rejection of hexavalent chromium by nanofiltration. Desalination 2008, 219, 171-178. [CrossRef]

17. Mnif, A.; Bejaoui, I.; Mouelhi, M.; Hamrouni, B. Hexavalent Chromium Removal from Model Water and Car Shock Absorber Factory Effluent by Nanofiltration and Reverse Osmosis Membrane. Int. J. Anal. Chem. 2017, 2017, 7415708. [CrossRef] [PubMed]

18. Mohammad, A.W.; Othaman, R.; Hilal, N. Potential use of nanofiltration membranes in treatment of industrial wastewater from Ni-P electroless plating. Desalination 2004, 168, 241-252. [CrossRef]

19. Lin, S.; Wang, T.; Juang, R. Metal Rejection by Nanofiltration from Diluted Solutions in the Presence of Complexing Agents. Sep. Sci. Technol. 2005, 39, 363-376. [CrossRef] 
20. Ates, N.; Uzal, N. Removal of heavy metals from aluminum anodic oxidation wastewaters by membrane filtration. Environ. Sci. Pollut. Res. 2018, 25, 22259-22272. [CrossRef] [PubMed]

21. Al-zoubi, H.; Rieger, A.; Steinberger, P.; Pelzc, W.; Haseneder, R.; Hartel, G. Nanofiltration of Acid Mine Drainage Nanofiltration of Acid Mine Drainage. Desalin. Water Treatmen 2010, 21, 1-14. [CrossRef]

22. Oatley, D.L.; Llenas, L.; Pérez, R.; Williams, P.M.; Martínez-Lladó, X.; Rovira, M. Review of the dielectric properties of nanofiltration membranes and verification of the single oriented layer approximation. Adv. Colloid Interface Sci. 2012, 173, 1-11. [CrossRef] [PubMed]

23. Alfa, L. Alfa Laval NF and RO Flat Sheet Membranes. Available online: https:/www.alfalaval.com/ globalassets/documents/products/separation/membranes/flat-sheet-membranes/nf-and-ro-flat-sheetmembranes_200000076-1-en-gb.pdf (accessed on 12 February 2020).

24. Meschke, K.; Hansen, N.; Hofmann, R.; Haseneder, R.; Repke, J.U. Characterization and performance evaluation of polymeric nanofiltration membranes for the separation of strategic elements from aqueous solutions. J. Memb. Sci. 2018, 546, 246-257. [CrossRef]

25. The Danish Environmental Protection Agency. Tilslutning af Industrispildevand til Offentlige Spildevandsanlæg; The Danish Environmental Protection Agency: København, Denmark, 2006.

(C) 2020 by the authors. Licensee MDPI, Basel, Switzerland. This article is an open access article distributed under the terms and conditions of the Creative Commons Attribution (CC BY) license (http://creativecommons.org/licenses/by/4.0/). 